\title{
NFC Based Intelligent Bus Ticketing System
}

\section{Rajshree Hargude, Aarti Kamthe and Prof. Vinod Badgujar}

Department of Computer Engineering Shree Ramchandra College of Engineering Pune, Maharashtra, India

\begin{abstract}
As the India is one of the fastest growing economies in the world, the Indian urban population has a large dependency on buses for public transport, providing importance of transport within urban/rural area throughout the country. In the public transport various problems are faced like traffic jam, confusion and misunderstanding between the passengers regarding fares, having several security problems in public transport due to antisocial elements, etc. For making the life more convenient for the computer travelling in buses some new technologies can be used like Near Field Communication (NFC) and Radio Frequency Identification. The proposed system is based on ticketing of bus and tracking of bus. The system suggests a automated ticketing system which will automatically cost will deduct the passengers fare according to the distance travelled.
\end{abstract}

Keywords : NFC, RFID, IOT.

\section{INTRODUCTION}

With population of over a billion people, India has one of the most heavily used public transport system in world. According to the National Sample Survey Organization(NSSO), most of the money for daily commute via public transport in India is spend for buses. Considering this, the issue of improving this mode of transport is now being given higher priority. India's urban population has great contribution to this growth. It is estimated that by 2031, India's population will reach around 600 million. Given that, public transportation in these areas has the potential to pool in a great amount of revenue. However, the transport facilities that are available at present are highly inadequate and inefficient. In today's scenario, it is essential to develop these dacilities in order to make them more dependable and convenient, hence less chaotic for the public. Internet Of Things, that is IOT, is an upcoming field that is gaining, increasing popularity in today's world. IOT devices are those that are connected to each other as well as to cloud servers through internet. IOT plays a key role in areas such as communication, automation as well as cost savings. In today's world, IOT is increasingly being used in various sectors such as agriculture, healthcare and transportation. Also, with the development in technology, more people are now making epayments such as for buying tickets for transport, instead of relying on cash transactions. Many countries around the world such as Denmark, Singapore, South Korea, Hong Kong etc have successfully adopted e-ticketing systems for public transportation. The introduction of this system has led to time saving and subsequently greater effectiveness in the transactions. Additionally, the integration of new technologies such as Near Field Communication (NFC) with IOT has helped in making people's lives easier. A smart payment system which eliminates the conventional concept of paper based ticketing proposed. The current method that is utilized for collection of tickets in public buses in India requires the bus conductor to navigate through a jam-packed bus in order to give out tickets to 
personally make the transaction with each passenger, which is quite hectic and, at times, chaotic, if a passenger has gotten from the back door, and needs to get down at the next bus stop, it becomes difficult for him/her to obtain the ticket quickly. Adopting the proposed system will decrease the frustration experienced by both the bus passengers as well as the ticket conductors. Hence it will become easier, as well as faster, to buy bus tickets via e-payments.

\section{LITERATURE SURVEY}

The existing system has an idea for implementing smart card ticketing technology for the passengers traveling in an exceedingly bus supported RFID technology. For this purpose, associate interface is made between RFID system and driver's mobilephone using a specifically developed with Android application referred to as "SwipeNgo" via Bluetooth. This technique uses associated AVR microcontroller unit to speak with the RFID reader for read the tag-id of traveler and causation the data to the driver's android phone. The application calculates the fair while exiting and deducts the number in main balance in card hold in a database. A displaying traveler information-entry, exit, card validity etc is employed. This paper proposes a easy automatic ticketing system. They need through of elimination of a paper primarily based ticketing system due its issues and have advance a technique of mistreatment RFID based smart cards that permits cashless payment with reusability. This technique additionally uses GPS to trace stoppage. Associate interface supported NFC and $\mathrm{QR}$ code for good sensors for rising the security is already exist. It proposes transfer of configurations of sensors mistreatment NFC and QR codes. One of the advantages of NFC technology is that it is more secure than wireless technology. Also, there is protection from attacks thanks to a restricted vary of communication. Moreover, it is straightforward and intuitive to use. The approach is planned to use in each smarter homes and factories. NFC is recommended to transfer configuration information from the mobile device to the smart sensonning device. As QR code has size limitation for payload transfer, it's not most popular. The proposes NFC services uses peer-to-peer (node to node) mode. NFC could be a proximity communication technology that's supported by smartphones or client devices and appears like a promising companion technology for the Internet-Of- Things(IOT). It's employed in applications like payment, access management, transport and a lot of usually for the exchange of tiny items of knowledge. The author says that IOT depends on smart-objects communication in peer-topeer mode or through the internet Network. NFC is employed for payments, access management or transport services; small pieces of information such as secret codes or cryptograms concerned in payment operations, area unit changed within a couple of centimetres. The author presents a detailed description of the NFC technology with operating and NFC P2P Model mistreatment secure elements (SIM) as a micro controller.

\section{SYSTEM DESCRIPTION}

\section{A. Working of passive NFC}

NFC works in 2 modes active and passive. A passive device, that is NFC tag, contains information that reader devices can read but doesn't read any info itself. Reading information is nothing however transmit the info to approved devices. NFC provides bi-directional communication for info transformation. NFC devices will send and receive information at same time. NFC tags contain data and are typically this is read-only data but may be rewriteable. The tag can securely store personal data such as Aadhar id-number, bank details, debit card, mastercard information. NFC Forum defines four kind tags which offer completely different communication speed and capabilities in 
terms of configurability, memory, security, information retention and write endurance, tags have between ninety six to 4096 bytes of memory. NFC communicates via magnetic/flux field induction, wherever 2 loop antennas are located within each other's which is called near field, effectively forming associate air-core transformation. NFC tag operates within the globally on the market and unauthorized radio frequency ISM band of $13.56 \mathrm{MHz}$, with a bandwidth of virtually two $\mathrm{MHz}$. Its operating distance restricted up to twenty $\mathrm{cm}$ with compact antennas.

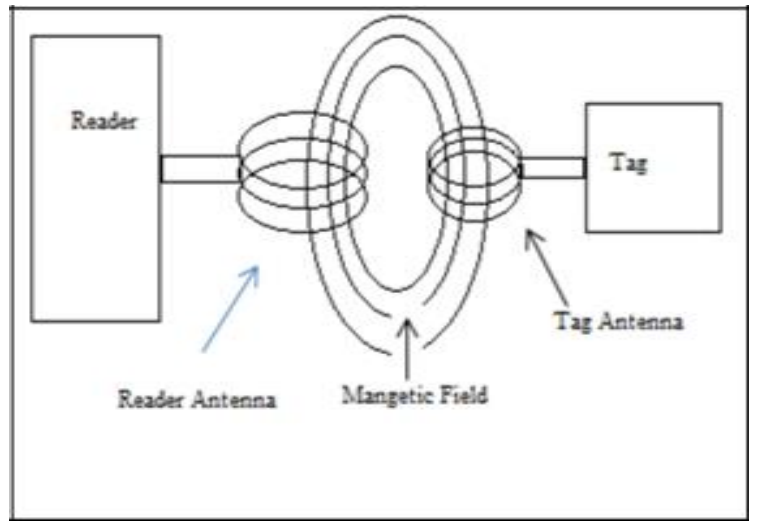

Fig.1. Working of Passive NFC

In passive mode the reader device provides a carrier field and therefore the NFC tag answers by modulating existing field. During this mode, the NFC tag could draw its operative power from the readerprovided magnetic force field.

\section{B. System architecture}

The system uses Arduino Mega 2560 as a microcontroller. The system is made IoT compatible by creating use of ESP8266. 2 NFC readers area unit employed in the system. The primary NFC reader is employed for entry within the bus. When the first NFC reader reads a NFC tag it saves the Boarding Location of the user. Once the second NFC reader reads identical NFC tag it saves the Dropping Location and calculates the fare.
The calculated fare is then subtracted from the Account Balance of the user. All this transactions are displayed instantaneously at both Entry gate likewise as Exit gate using I2C digital display. Light emitting diode indications are also provided at each entry and exit gates. Associate android app are designed to recharge the NFC tags from the phone itself. Thus there's no got to attend the Ticketing Section for recharging the tags. All the user information would be saved on a cloud server.

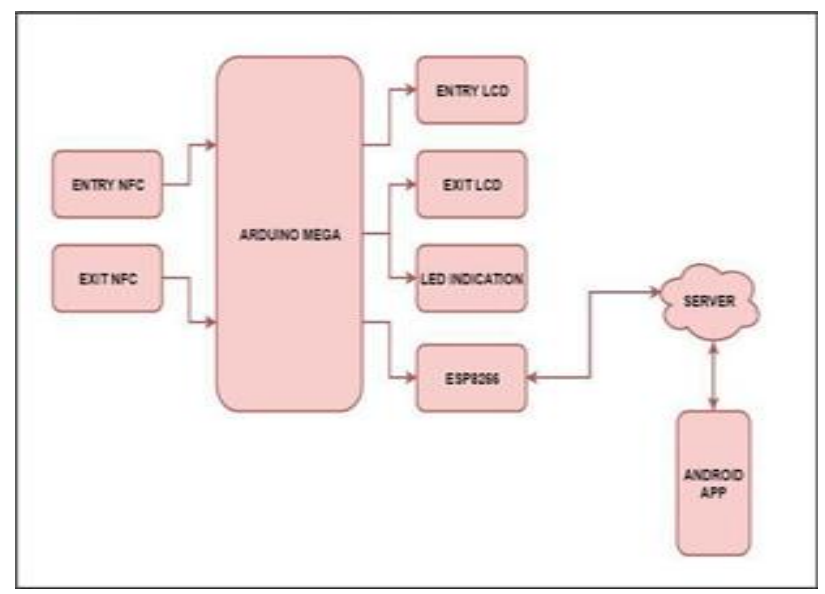

Fig.2.System Architecture

C. System overview

The system consists of one NFC sign on terminal and one NFC sign out terminal. At first the user needs to register to the application before boarding the bus. Once traveler entered in the bus they're needed to tap their phone on the NFC sign on terminal. The NFC reader sends the tag info to server and server fetches the placement of traveler. NFC server send sign on notification to travelers mobile Application. Subsequently virtual Ticket is get generate on the mobile Application. 


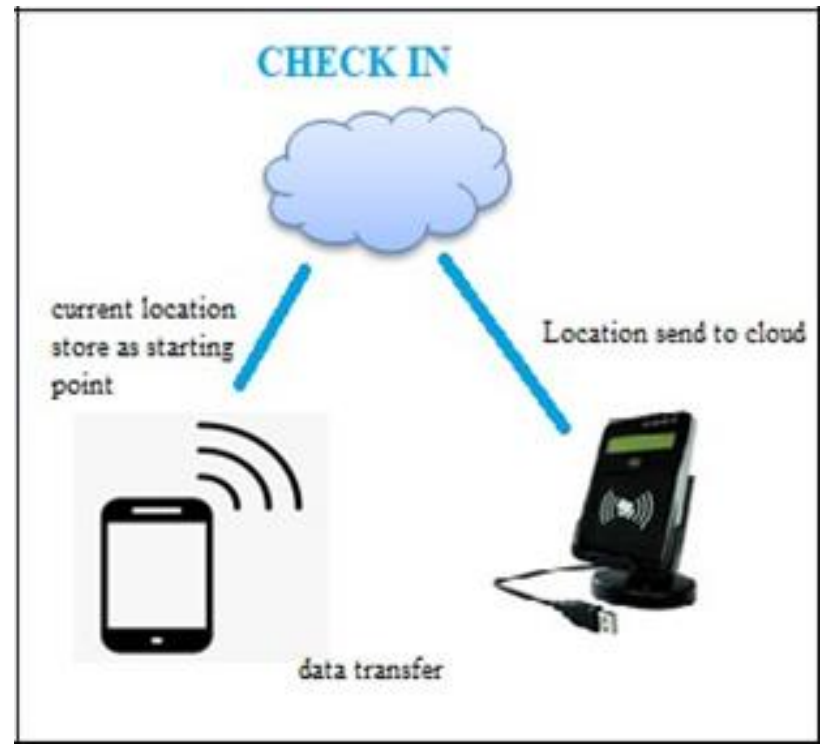

Fig.3. Sign-On Procedure

When the traveler reaches his destination and needs to down from the bus he needs to tap his/her phone on the NFC sign out terminal. Then the sign out location is send to the server and Application. At the backend the whole distance is calculated and consistent with the distance the fees is automatically subtracted from the travelers account. If traveler getin the bus while not get in-tuned of NFC reader, when traveler journey is completed and whereas he gets down from the bus and came to contact with the reader total fare will be subtracted from his account thus by this cheat-proof way to build bus payment is planned.

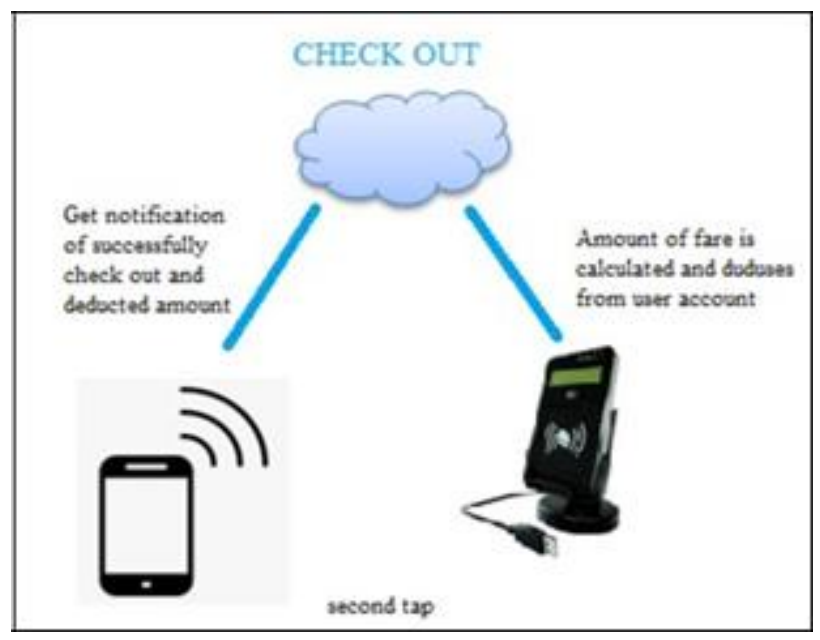

Fig.4. Sign-0ut procedure
D. Flowchart

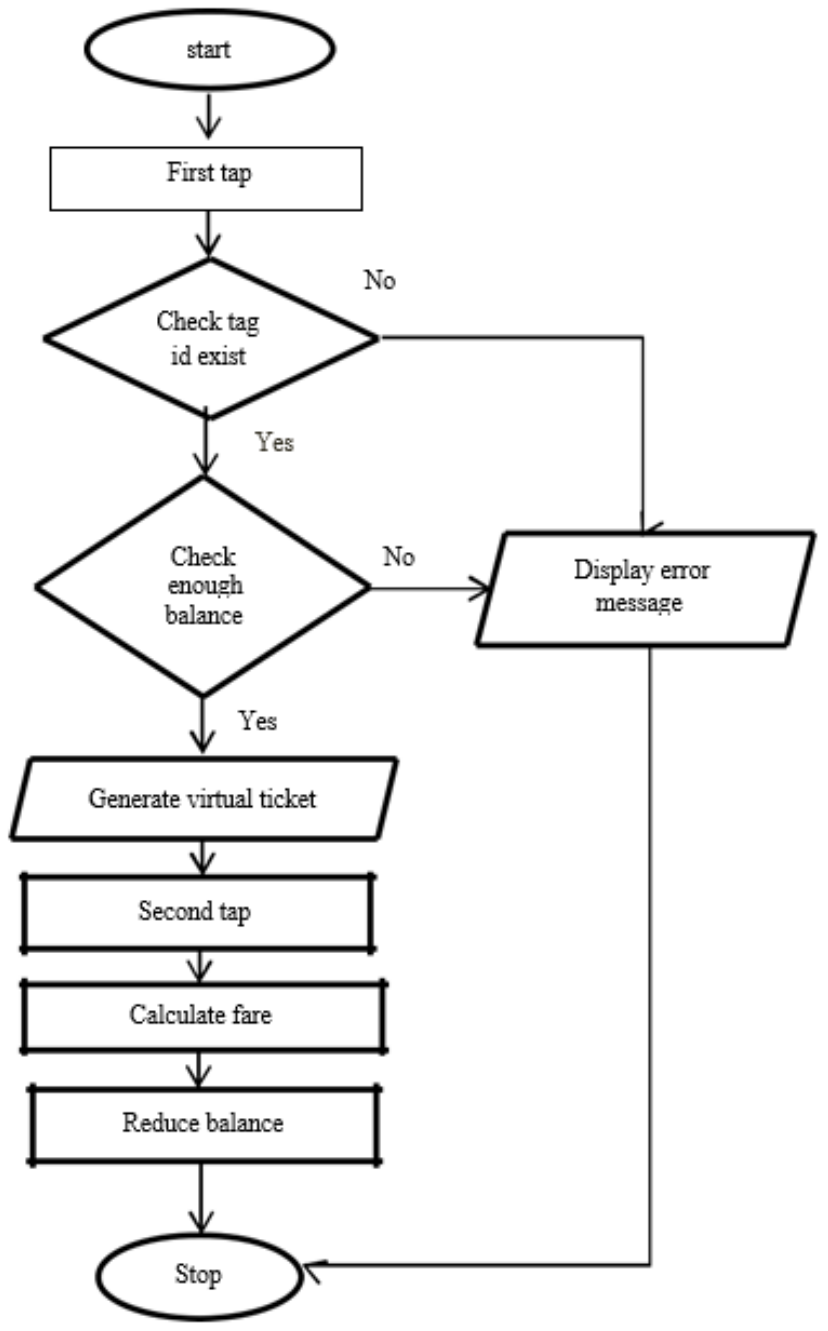

IV.CONCLUSION

We aim to implement a Bus Ticketing System with NFC Technology. The system is enforced to get NFC tickets, so reducing human effort and creating the process completely automatic system. NFC tickets helps in identifying people travelling within the bus providing security. The passengers solely got to carry their NFC tags and recharge their account once the balance is below the desired fare worth. The cards being reusable, they're for more convenient compared to the traditional ticketing system because it eliminates wastage of papers. This technique even helps to stay the record of the whole expense of the 
bus and provides bus routes, schedule and fare. Any unwanted events will be avoided as all the person carrying NFC tickets are monitored each time they travel as their details are recorded at the server facet info.

\section{REFERENCES}

[1]. Dr. P. Chowdhury, P. Bala, D. Addy, S. Giri, A. R. Chaudhuri, "RFID and Android based ticketing system and destination announcement system," in Intl. Conference on Advances in Computing, Communication and Informatics(ICACCI), sep. 2016.

[2]. Maithili Dhule "NFC Based Smart Urban Public Bus Transport Payment System." in 2018 3rd International Conference for Convergence in Technology (12CT). Apr 06-08, 2018.

[3]. V. Odelu, A. K. Das and A. Goswami, "SEAP: secure and efficient authentication protocol for NFC applications using pseudonyms," IEEE Transactions on Consumer Electronics, vol. 62, no. 1, pp. 30-38, 2016.

[4]. T. Ulz, T. Pieber, C. Steger, "SecureConfig: NFc and QR-Code based Hybrid Approch for smart Sensor Configuration," in IEEE Intl. Conference on RFID, 2017.

[5]. P. Urien, "LLCPS: A New Secure Model for Internet of Things Service Based On The NFC P2P Model," in IEEE ninth International Conference on Intelligent Sensors, sensors Network and Information Processing(ISSNIP), Symposium on Security, Privacy and Trust forCyber-Physical System, Singapore, 21-24 April 2014.

[6]. T. Dahlberg, J. Guo, and J. Ondrus, "A critical review of mobile payment research," Electronic Commerce Research and Applications, vol. 14, no. 5, pp. 265-284, 2015.

[7]. J. Morak and G. Schreier, "Design and evaluation of near field communication (NFC) technology based solutions for mHealth challenges," in Mobile Health. Springer, 2015, pp. 813-838.

[8]. NFC Forum, "NFC in Public Transport," Jan 2011.[white paper], Web. https//nfc-forum.org

[9]. ENS Economics Bureau, “GDP: At 7.6\%, India's growth points to fastest growing large economy." Indian Express, 2016. Web. http://indianexpress.com

[10]. T. Ramachandran, "India relies mainly on buses for transportation, but they are being marginalized." The Hindu, 2016. Web. http://www.thehindu.com

\section{Cite this article as :}

Rajshree Hargude, Aarti Kamthe and Prof. Vinod Badgujar, "NFC Based Intelligent Bus Ticketing System", International Journal of Scientific Research in Science and Technology (IJSRST), Online ISSN : 2395-602X, Print ISSN : 2395-6011, Volume 7 Issue 2, pp. 283-287, March-April 2020. Available at doi : https://doi.org/10.32628/IJSRST207213 Journal URL : http://ijsrst.com/IJSRST207213 